\title{
Lithium Circuit Test Section Design and Fabrication
}

\author{
Thomas Godfroy and Anne Garber \\ NASA MSFC, ER11, Huntsville, Alabama, 35812 \\ (256) 544-1104, Thomas.Godfroy@nasa.gov,Anne.E.Garber@nasa.gov
}

\begin{abstract}
The Early Flight Fission - Test Facilities (EFF-TF) team has designed and built an actively pumped lithium flow circuit. Modifications were made to a circuit originally designed for $\mathrm{NaK}$ to enable the use of lithium that included application specific instrumentation and hardware. Component scale freeze/thaw tests were conducted to both gain experience with handling and behavior of lithium in solid and liquid form and to supply anchor data for a Generalized Fluid System Simulation Program (GFSSP) model that was modified to include the physics for freeze/thaw transitions. Void formation was investigated. The basic circuit components include: reactor segment, lithium to gas heat exchanger, electromagnetic (EM) liquid metal pump, load/drain reservoir, expansion reservoir, instrumentation, and trace heaters. This paper will discuss the overall system design and build and the component testing findings.
\end{abstract}

\section{INTRODUCTION}

The Early Flight Fission - Test Facility (EFF-TF) was established by NASA's Marshall Space Flight Center Propulsion Research Center Nuclear Propulsion Group to provide a capability for performing hardware directed activities relevant to multiple nuclear power reactor concepts using non-nuclear test methodology. This includes fabrication and testing at both the module/component level and near prototypic hardware configuration allowing for realistic thermal hydraulic evaluations of systems. In addition, equally important to the actual hardware development are: 1) experience/knowledge gained during fabrication and assembly, 2) the development of documentation/procedures related to both integration and operation (includes both test hardware and facilities) and, 3) the experience gained from early hardware testing with both relevant materials and environment (producing insight and lessons learned for the hardware development program). From an array of possible reactor/primary heat transport systems applicable to space based power and propulsion, the EFF-TF was tasked to examine an actively pumped alkali metal (Li) circuit by the Naval Reactors Prime Contract Team (NRPCT). During the development of this system, required facility interfaces were leveraged using existing EFF-TF capabilities and test hardware wherever possible.

The intent of this work was to gain experience with a lithium liquid metal system and to begin to understand the nature of liquid lithium, freeze/thaw issues, and operational issues. Specific objectives included:

- Design, fabricate, assemble, and operate a small-scale stainless steel actively pumped liquid metal (lithium) flow circuit.

- Gain circuit experience with lithium such that this experience can be transferred, where applicable, to follow-on design and testing of a high temperature, refractory metal actively pumped lithium circuit.

- Investigate the nature of freeze/thaw issues though hardware testing.

- Include, by design, the ability to perform component testing of nominally sized components that may be of interest to NRPCT.

- Document lessons learned for future applications as much as possible.

\section{STAINLESS STEEL LITHIUM CIRCUIT (SLIC) LAYOUT}

Figure 1 identifies the key system elements of the stainless steel lithium flow circuit. The complete system is mounted on a tilt table (making it modular) that is inserted into the EFF-TF 9-ft vacuum chamber (ref TBD). The interfaces/connections with the vacuum chamber include instrumentation, pump/heater power, pump cooling, valve control power, and a secondary He/Ar closed cycle coolant loop (no lithium is routed out of the vacuum chamber). The lithium circuit is of an all-welded construction with the exception of a few strategic locations to attach instrumentation such as the liquid level sensors, pressure transducers, and test section connection/disconnection points. These connections are all made with VCR fittings. All components and tubing have been proof pressure tested to greater than 300 psi and leak checked using gaseous helium (GHe) to better than $10^{-9} \mathrm{SCCM}$ to minimize the potential of leaks. High temperature valves (remote operated where needed) are specified in the lower reservoir. 
Instrumentation measurements are made at key locations including the core, heat exchanger, reservoir and pump as well as at necessary points throughout the circuit.

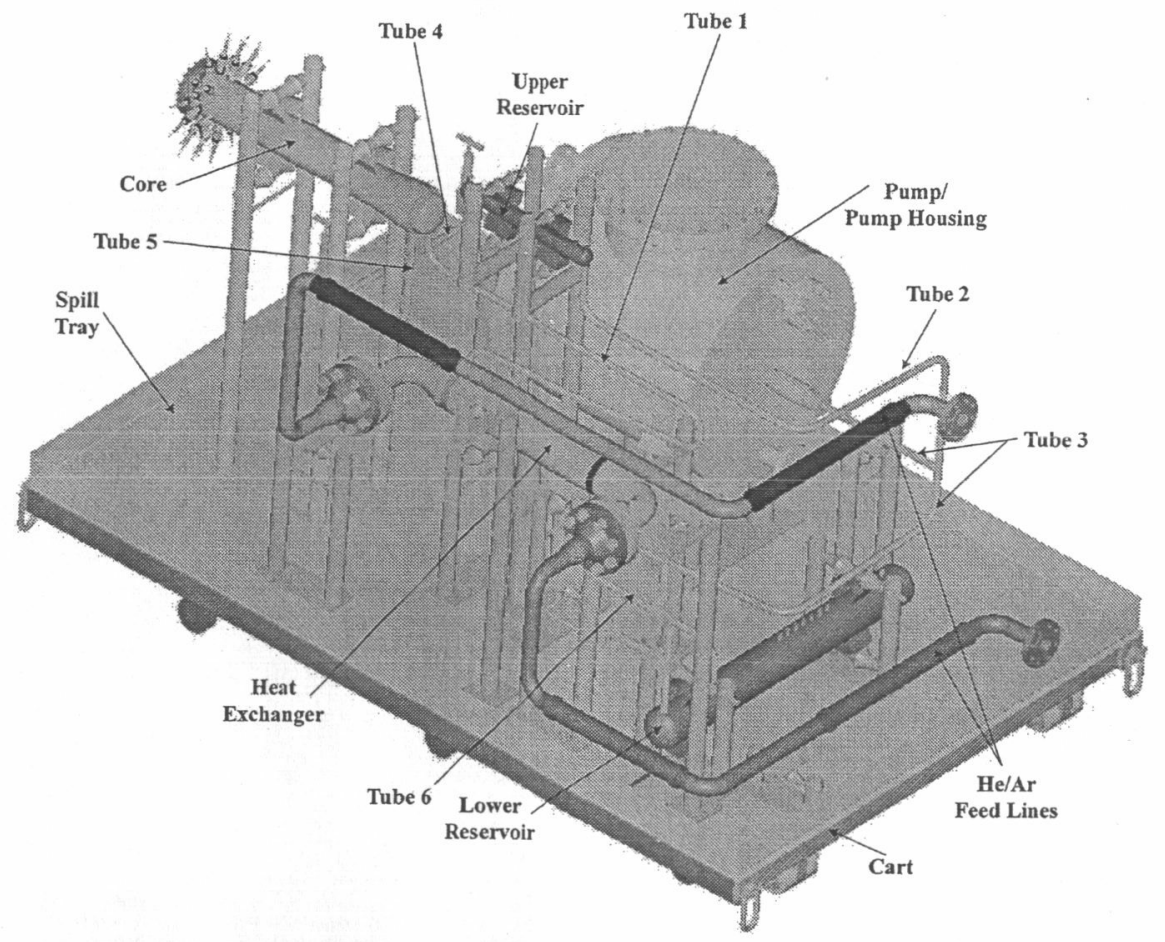

FIGURE 1. Schematic for Stainless Steel Lithium Thermal Hydraulic Flow Circuit.

All components are constructed from stainless steel, primarily 316, with the exception of the level sensors. The ceramic portions of sensors do not come in direct contact with the lithium. Figure 2 shows the as-built test circuit.

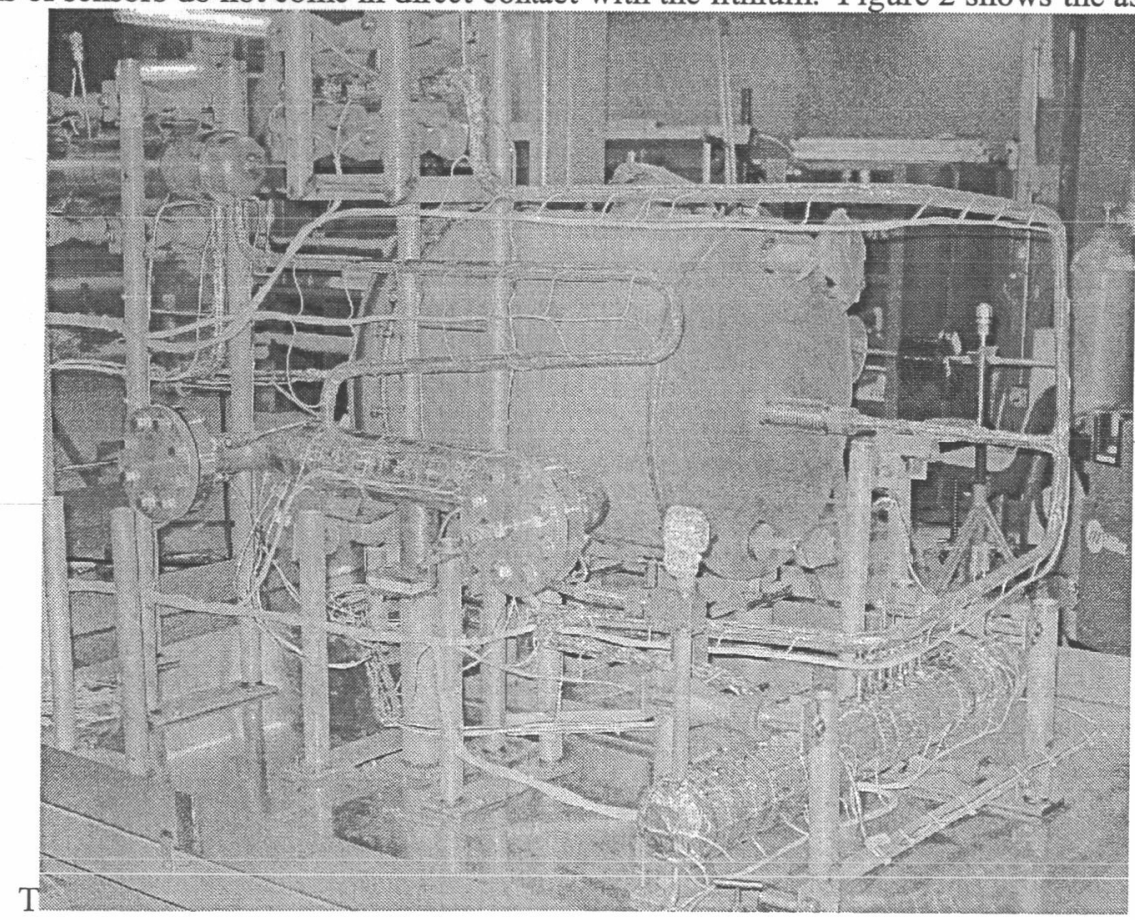

FIGURE 2. Test Loop as Built (He/Ar Feed Lines Not Shown).

The overall layout of components and tubing was engineered to provide sufficient flexibility without the use of expansion bellows in the circuit. Bellows were avoided since they are a thin walled component susceptible to mechanical damage and the convolutes can retain residual lithium making draining/clean up more difficult. 
Additionally, butt-welds were used wherever possible to eliminate possible cavities in which lithium and impurities could be trapped. The flow circuit was designed for use on a tilt table, providing a "low spot" to utilize gravity to route the lithium to the fill/drain vessel (lower reservoir). In the smaller diameter tube sections, such as in the pressure transducer standoffs, a purge of high purity argon was envisioned to overcome the surface tension of the lithium and to purge the lines of the liquid lithium. In general, major flow components are placed to limit pressure drop (large flow areas) so as to maximize flow rate and to minimize pump power consumption.

\section{TRACE HEATING AND INSULATION}

Trace heaters are placed on nearly all circuit components and tubing such that the entire system can be heated to approximately $525^{\circ} \mathrm{C}$. The trace heaters used are Watlow brand cable heaters that are stainless steel sheathed, $1 / 8^{\prime \prime}$ diameter cold formable, $240 \mathrm{~V} \mathrm{AC}$ resistance heaters capable of continuous operation at temperatures up to $650{ }^{\circ} \mathrm{C}$ with intermittent operating periods achieving up to $815^{\circ} \mathrm{C}$. These heaters were cold formed to fit as snugly as possible along all sections of tubing and all major components except the core. An attempt was made to provide two trace heaters for each section being heated and to make logical sections for control of thermal input into the system. Because these heaters will be operated in a vacuum, a type- $\mathrm{K}$ thermocouple is embedded in or adjacent to the heater to monitor the temperature and to prevent burn-up. The heaters were clamped in place with wire ties and several layers of copper foil were tightly pressed around the heater and tube. The copper allows the heat from the portion of the heater not in contact with the tube to be dispersed more evenly about the tube and the copper allows the heater to expand and contract as need. Due to the thermal mass difference and the material type difference, the rates of expansion of the heater and tube was significant enough to cause heater failure. Additionally, a minimum of two layers of multi-layer insulation (MLI) is stood off (not shown) via wire standoffs from the tubes. This reduces radiation losses, which are the most dominant heat loss mechanism in a vacuum. Each of the components is wrapped in a similar manner.

\section{CORE}

The liquid metal circuit was designed around the core design. While this core design was based on a NaK design study, the application of this design to a working lithium design will still have significant merit. The core geometry for this project is based on a 100-kWt study (Poston, 2003) performed by the Los Alamos National Laboratory that utilizes annular fuel pins and two-pass coolant flow.

The core assembly is oriented horizontally, simplifying heater installation and relying on sufficient table tilt for complete drainage. It is constructed of stainless steel 316 (all welded configuration) and inspected by a complete radiographic survey and helium leak detection. The complete core assembly consists of six primary components: core block, outer pressure shell, inlet plenum, outlet plenum, lower manifold, and fuel pin clad.

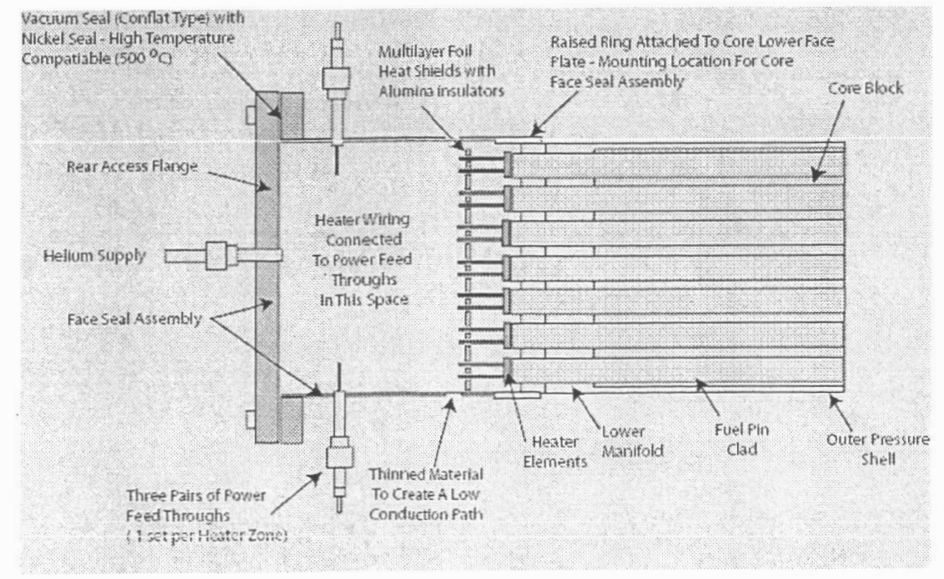

FIGURE 3. Simplified Schematic Core Face Sealing System.

The heater elements selected for this system were based on a graphite design that has been successfully used on a number of prior EFF-TF projects. The graphite heater element has a diameter of $0.775 \mathrm{~cm}$ with an overall length of $59.7 \mathrm{~cm}$. The heater element is equipped with alumina-insulating rings that measure $1.27 \mathrm{~cm}$ in length with an 
outside diameter of $1.067 \mathrm{~cm}$. The elements are positioned approximately $4.5 \mathrm{~cm}$ into the core as measured from the outer surface of the lower manifold faceplate. Each heater has a resistance of approximately 0.9 obms at room temperature and $0.5 \mathrm{ohms}$ when at an operating temperature of $700{ }^{\circ} \mathrm{C}$. The baseline approach requires that heaters be assembled in zones that are connected to individual power supplies (1 power supply per zone). Each power supply is rated for $15 \mathrm{~kW}$ of DC power delivered via $150 \mathrm{~V}$ at $100 \mathrm{~A}$ maximum. The 37-pin core assembly is divided into three control zones. The grouping of heaters in these zones (series/parallel) is laid out such that the equivalent resistance attempts to maximize the power supply output capability.

To improve the thermal performance of the 37-pin lithium system there is a core face sealing assembly. This assembly, which is attached to the power inlet end of the core, allows for a helium environment to be established between the fuel cladding and the heater, significantly improving the overall thermal conductivity (coupling) between the heaters and core clad. This better simulates the thermal conditions in the actual core in which helium gas within the fuel pin provides excellent heat transfer across the pin. Figure 3 illustrates this concept.

\section{HEAT EXCHANGER}

Once the lithium coolant is heated by the core assembly to a temperature of approximately $500{ }^{\circ} \mathrm{C}$ it passes into a heat exchanger to remove up to $40 \mathrm{kWt}$. The baseline for this heat exchanger was a "battleship" or facility-style design that provides significant robustness in this initial flow circuit. It is a 0.6 meter long counter-flow design with lithium confined by the outer jacket $(14.1 \mathrm{~cm}$ outer diameter) and the secondary coolant flow (a gas, either HeAr or $\mathrm{N}_{2}$ in this application), confined by 107 tubes $(0.8 \mathrm{~cm}$ outside diameter) that pass through the lithium flow pool. The exchanger is equipped with temperature and pressure measurements to monitor material and fluid conditions. Two 65 " long, $240 \mathrm{~V}, 675 \mathrm{~W}$ Watlow cable heaters were positioned on the heat exchanger to provide heat during a thaw start-up condition or as needed during filling or transient operations. It is not anticipated that these trace heaters would be required during steady state operations. One trace heater was positioned on the top and one on the bottom of the heat exchanger. Each heater has two thermocouples positioned between the trace heater and the heat exchanger body to provide feedback temperatures for automatic control of the system. Additional type- $\mathrm{K}$ thermocouples are spot welded at various locations around the body to provide temperature information. The affixed trace heaters and thermocouples are then wrapped with 0.003" copper foil to aid in thermal conduction from the trace heater to the body. Any gaps between the trace heater and the core body would result in localized heating of the trace heater and this excess temperature could result in trace heater failure. Additionally the copper wrap allows the trace heater to grow and contract as needed due to the differing rates of expansion caused by the temperature difference between the trace heaters and the heat exchanger.

\section{PUMP \& HOUSING}

An electromagnetic pump was selected as the baseline both to maintain the integrity of the all-welded flow loop with no moving parts and to build experience with a pump type that is applicable to a space power system. This pump is a Style-VI two-stage AC conduction unit with a stainless steel 316 duct, the design of which dates back to the 1950s. It provides continuous operation at temperatures up to $816^{\circ} \mathrm{C}$, with flow control from 10 to $100 \%$ (control provided by a 3-phase motor driven variable transformer). The Style-VI pump makes use of a flattened flow duct in the pumping stages; therefore, the pressure differential across the piping is limited to prevent circularization of the duct and pump failure. Nominal operation of the 37-pin system will require a pressure differential (relative to vacuum) of approximately $140 \mathrm{kPa}$. This pressure drop is within the pump's limits.

Due to the heat generated by the pump and the temperature limitation of the commercial magnet coils, a stainless steel pump enclosure has been designed so that a gaseous nitrogen cooling purge can be provided to the unit while in operation at high temperature. The pump enclosure is necessary since the entire system will be placed in a vacuum chamber with pressure conditions of $10^{-5}$ torr or lower, eliminating natural convective cooling of the pump.

\section{LOWER \& UPPER RESERVOIRS}

A lower reservoir (LR) has been placed at the lowest elevation of the system to serve as a storage vessel for both the fill and drain operations. The LR also serves as the storage tank for the lithium between tests. After the system has been baked out, the lithium will be loaded molten from the fill pot in the tube shown in Figure 6. Once loading from the fill pot tube is completed, this tube would be connected to a pressurization system that would supply low pressure argon, measured with an Astro sensor pressure gauge located at LRPG1. During fill operations, applying 
pressure to the top of the liquid metal will force the liquid up and into the evacuated tubes of the circuit via the $\mathrm{To} /$ From Circuit tube that extends to the bottom of the LR. The fill/drain valve (a Swagelock SS-12UW Series valve using a Series 8 Actuator, not shown) located between the LR and the circuit on the To/From Circuit tube (see Figure 4) was specified for remote operation. Three 93" long $240 \mathrm{~V}, 1000 \mathrm{~W}$ Watlow cable type trace heaters were positioned on the LR (shown as red lines in Figure 4) to provide heat that will be required to melt the lithium before introduction into the system for a test. Void formation in the LR will occur at the top of the reservoir due to gravity; therefore, controlled freeze/thaw is desirable and can be accomplished using the trace heaters in a specified configuration.

There are 23 thermocouples (LRTC1..23) spot-welded to the LR. In addition to providing bulk temperature data LRTC1..6 and LRTC10..15 have been placed to provide a second method of level sensing. There are seven level sensors installed in the LR. These sensors use a single stainless steel pin; only the sensor pin comes in contact with the liquid metal. The system functions by using one sensor, LS1, as the common ground; the balance of the sensors complete a circuit to indicate fill level in the presence of the lithium. Calculations indicate that the lithium will rise to a height between LS6 and LS7 at the fill temperature, $\sim 250^{\circ} \mathrm{C}$.

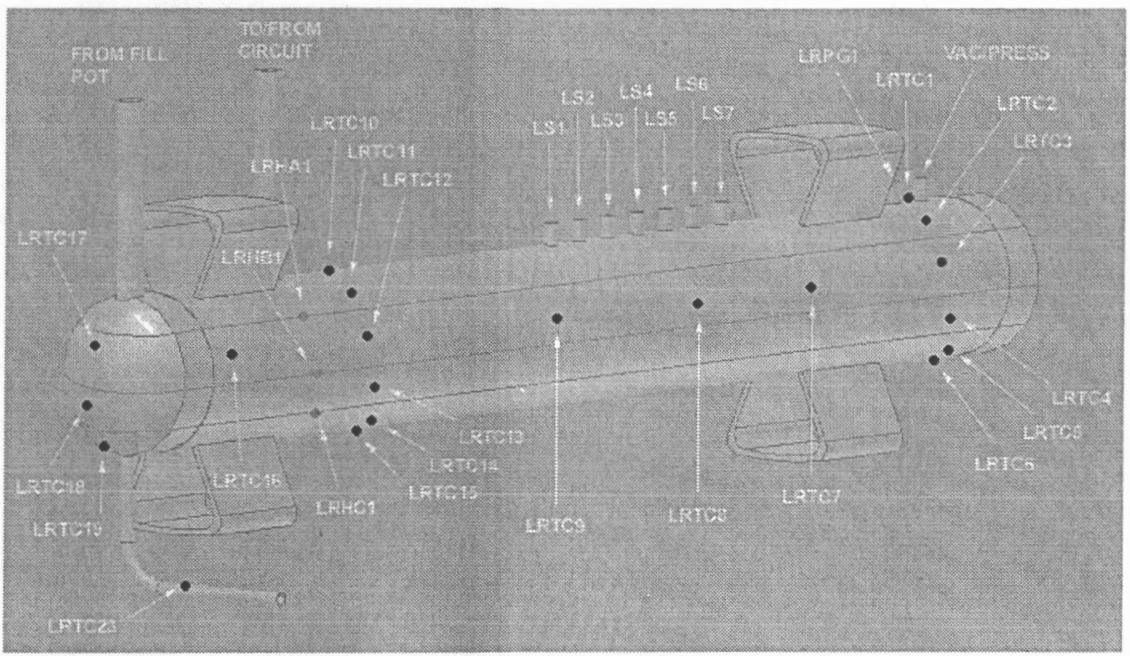

FIGURE 4. Lower Reservoir Instrumentation and Trace Heater Location, Front View.

Because the fill/drain reservoir was relocated to the lowest height in the circuit, an additional volume, the upper reservoir (UR), was required accommodate the difference in thermal expansion of the lithium between the fill temperature, $\sim 250{ }^{\circ} \mathrm{C}$, and the operational temperature, $\sim 500{ }^{\circ} \mathrm{C}$. This required volume is located at the highest point in the system. During operation, the top of the upper reservoir would be pressurized with ultra high purity argon (at relatively low pressure) to maintain a pressure head on the system to prevent the EM pump from oscillating rather than circulating. This same pressurization system was also intended for use in drain procedures to drive the lithium out of the UR. One 47" long $240 \mathrm{~V}, 345 \mathrm{~W}$ Watlow cable type trace heater was placed on the UR to replace the thermal power that is lost to the environment and to provide control during freeze and thaw experiments. There are three thermocouples spot-welded to the UR, providing gross temperature data for monitoring or debugging, and three level sensors (one each for the high and low level indicators and ground). The entire UR was wrapped with copper foil.

\section{TUBING}

The circuit tubing is formed from seamless 316 stainless steel tubing with a 0.095 " wall. This tubing connects all the components of the circuit. 1" VCR fittings are used to connect and disconnect Tube 4 (see Figure 3) from the system. These connections define the connection points for a test section where test ariicies could be attached and are available to mate any components to the circuit in the component test bypass area. Thermocouples were attached every six inches along the length of each tube. Two trace heaters are attached to each tube, attempting to place one on top surface and one on the bottom surface to allow for controlled freeze/thaw, forcing the void space to the top. However, since copper foil was required to disperse the heat from the heaters to avoid burn-up and to allow the 
heaters to expand and contract at different rates than the underlying tube, the ability to control the input thermal gradient to the tube was reduced due to the superior thermal conductivity of copper.

\section{Lithium Fill}

\section{PRELIMINARY TESTING}

Prior to filling the entire lithium circuit with lithium a small test article was filled. This test article was used to gain further experience with lithium and to gather data for the freeze thaw tests; however, an equal amount of experience and information was gained from the fill process. Figure 5 shows the fill apparatus in a horizontal orientation. The actual orientation was vertical to allow gravity to help the lithium move into the test article. Not shown are the tape heaters wrapped around the test article, transfer valve, and melt pot.

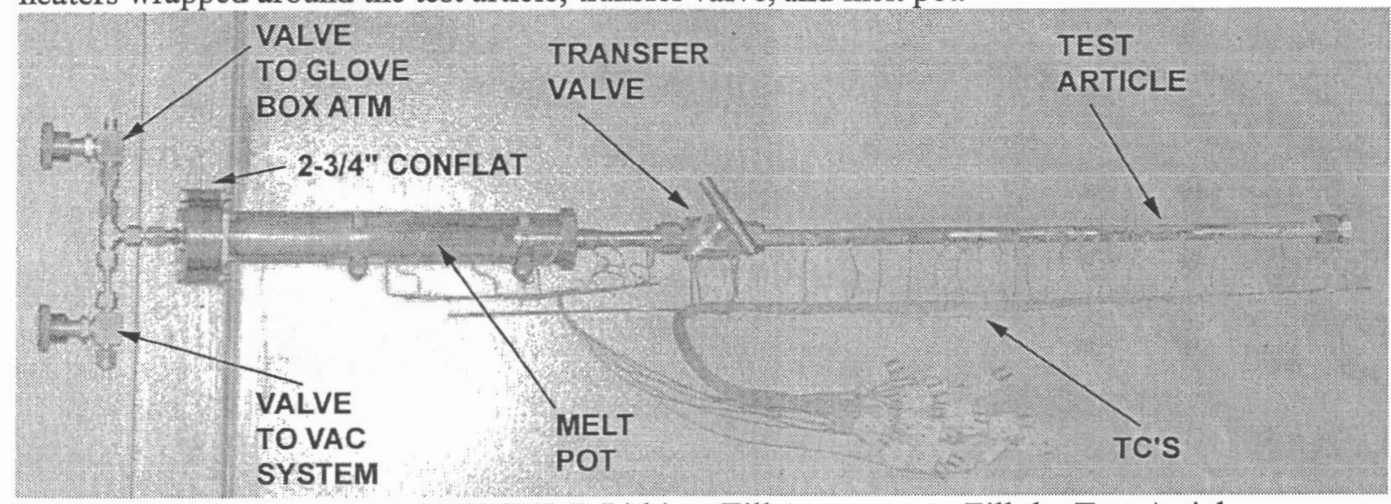

FIGURE 5. Lithium Fill Apparatus to Fill the Test Article.

To complete the test article fill, the melt pot was opened at the 2-3/4" Conflat flanges and pre-measured and weighed slugs of lithium were placed in the melt pot. The entire vessel was baked out until the vacuum remained stable at $10^{-5}$ torr prior to introduction of the lithium and again after the introduction of the lithium (the glove box atmosphere valve was closed and the vacuum valve was connected to a vacuum system with ion gauges). Following melt pot bake-out, a vacuum was trapped in the test article by closing the transfer valve while under vacuum. The lithium was melted to approximately $300{ }^{\circ} \mathrm{C}$ under vacuum and the melt pot gently tapped with a wrench until all the gasses trapped in the melted lithium had evolved, as indicated on the ion gauges. The lithium was introduced into the test article at $300{ }^{\circ} \mathrm{C}$ by isolating the vacuum system and opening the glove box atmosphere valve. When the transfer valve was opened, the transfer of the lithium to the test article was assisted by the pressure difference (vacuum in the test article and atmospheric pressure pushing on the lithium in the melt pot) and gravity to overcome any surface tension or friction. This transfer was monitored and verified by recording thermocouple data along the test article, the valve body, and the melt pot. The lithium in the test article was then raised to $375{ }^{\circ} \mathrm{C}$ and the transfer valve closed. When the lithium cooled, this left a void in the test article that was used in follow-on testing in attempt to understand void formation during freeze. Some of the most important lessons learned were:

- Solid lithium out-gases when melted.

- Thermocouples on the outside of the tubes normalize to the lithium temperature.

- Wetting can be accomplished (as predicted) at the test temperatures.

- The technique for introducing lithium was verified.

These lessons learned were applied to design and operation of the circuit.

\subsection{Lithium Freeze/Thaw Tests}

Freeze and thaw tests were performed to provide hands-on experience base with a freeze/thaw front, power heat loss values from the test section (article) to the environment, to investigate void formation, and to provide actual data for comparison to Generalized Fluid System Simulation Program (GFFSP) module results. These tests were conducted in a vacuum chamber using a cable heater to supply heat to the valve end of the test anticle, as shownin in Figure 6 . 


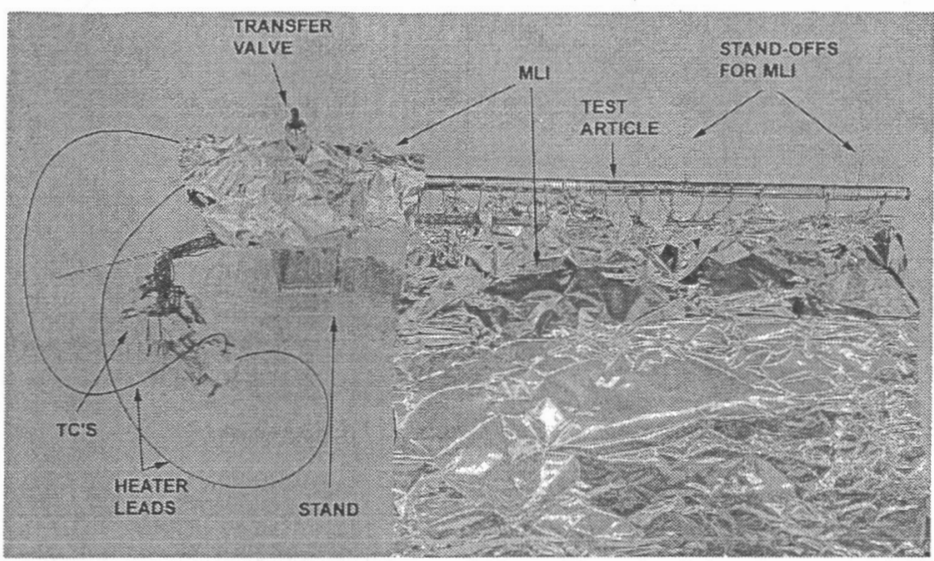

FIGURE 6. Freeze/Thaw Test Article.

The test article was mounted on a stand at the valve end with the heat load being applied at this end via a cable heater. Multilayer insulation (MLI) consisting of loose wraps of aluminum foil was wrapped around the test article (the test section is shown unwrapped in Figure 6). Thermocouples were located at measured distances and used to gather the temperature data, shown in Figure 7. Figure 8 shows a graph of data from a thaw cycle and Figure 9 shows data from a freeze cycle.

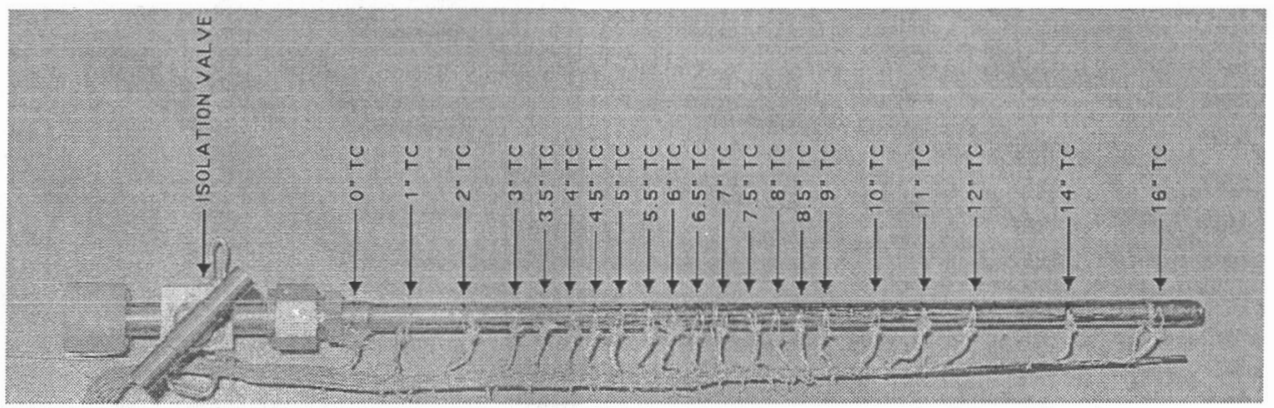

FIGURE 7. Freeze/Thaw Test Article with Thermocouple Identification.

Figure 8 shows a typical thaw temperature profile of the test article undergoing a thaw test. Power was applied to the trace heater wrapped at the valve end and the heat was allowed to propagate down the length of the test pipe. These experiments were conducted in a vacuum. Once the slopes of the temperatures approached zero the system was considered to be in equilibrium with the amount of power input equating the amount of loss due to radiation and a small amount to conduction through the base. Of interest to note is the perturbation in the slope lines at the melt temperature of lithium $\left(180^{\circ} \mathrm{C}\right)$.
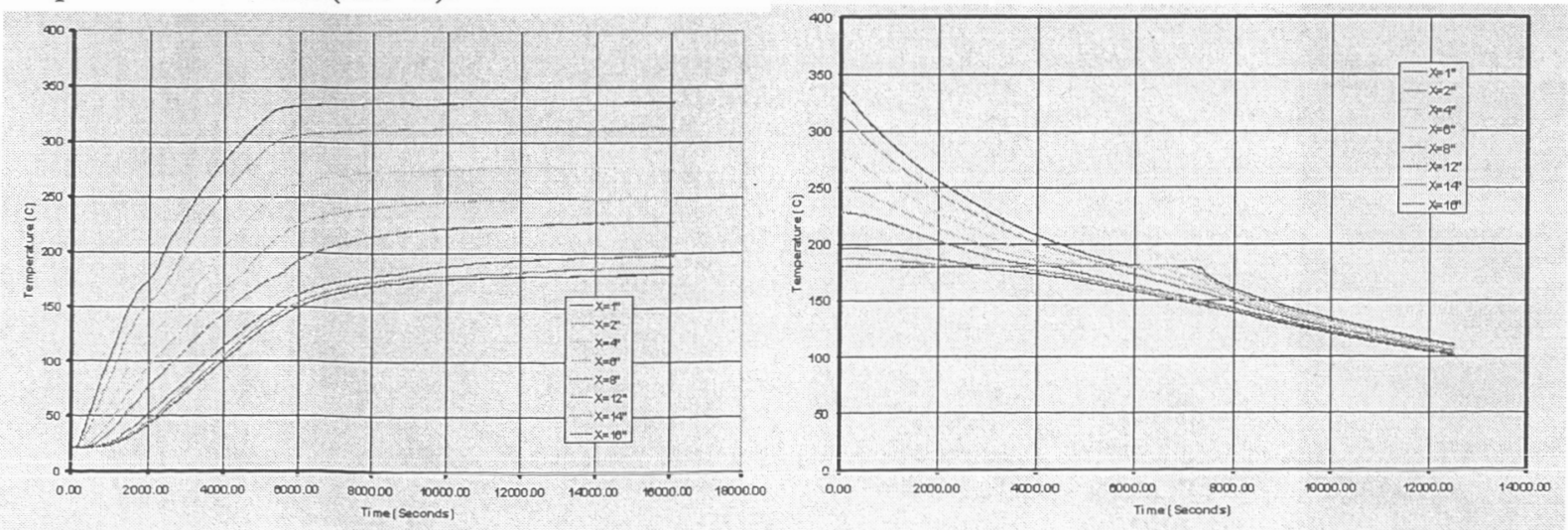

FIGURE 8. Measured Temperature Profile During a Lithium Thaw.

FIGURE 9. Measured Temperature Profile During Lithium a Freeze. 
Figure 9 shows a typical freeze temperature profile of the test article undergoing a freeze test. The test article was allowed to reach equilibrium then the power was cut to the trace heater and the test article allowed to cool. Of interest is the transition temperature from solid to liquid $\left(180^{\circ} \mathrm{C}\right)$ and how the lithium holds relatively constant at this temperature for a period of time before it freezes.

These initial experiments were performed with lithium to gain experience with handling lithium in solid form or in the liquid form at elevated temperatures, to better understand the behavior of void formation in lithium, and to take data that could be used to calibrate upgrades to a Generalized Fluid System Simulation Program (GFSSP) model. These upgrades would enable GFSSP to model the freeze/thaw of lithium in the system to ultimately produce a model that could be used to predict the freeze/thaw of a complete system. This ability would then aid in further designs of liquid lithium systems.

\section{SUMMARY}

The Early Flight Fission - Test Facilities (EFF-TF) team has designed and built an actively pumped lithium flow circuit. Modifications were made to a circuit originally designed for $\mathrm{NaK}$ to enable the use of lithium that included application specific instrumentation and hardware. Component scale freeze/thaw tests were conducted, successfully gaining experience with handling and behavior of lithium in solid and liquid form. Anchor data for a Generalized Fluid System Simulation Program (GFSSP) model was supplied to enable modifications that included the physics for freeze/thaw transitions. The basic circuit components include: reactor segment, lithium to gas heat exchanger, electromagnetic (EM) liquid metal pump, load/drain reservoir, expansion reservoir, instrumentation, and trace heaters where described as well as the overall layout of the circuit.

To Be Completed

\section{NOMENCLATURE}

\section{ACKNOWLEDGMENTS}

Many thanks to the following for the long hours and excellent work on this project: Roger Harper, Dr. Noah. O. Rhys, Alok Majumdar, Stan McDonald, Gene Fant, Kenny Webster, James Martin, Melissa Van Dyke, Eric Stewart. NASA's Project Prometheus supported the work described within this paper, in whole or part, as part of the program's technology development and evaluation activities. Any opinions expressed are those of the author and do not necessarily reflect the views of Project Prometheus

To Be Completed

\section{REFERENCES}

